\title{
Paisajes vemos, de su creación no sabemos. El paisaje agavero patrimonio cultural de la humanidad
}

\author{
José de Jesús Hernández López
}

CIESAS-OCCIDENTE

El artículo hace un análisis de algunas concepciones históricas del paisaje y del patrimonio, así como del uso pragmático que se hace en la actualidad de ambos conceptos. El caso elegido para sustentar el argumento es el de "El paisaje agavero y las antiguas instalaciones del tequila" declarados patrimonio cultural de la humanidad por la UNESCO en 2006. El marco para el análisis corresponde con la propuesta del moderno sistema mundo de Wallerstein y la división entre paisajes políticos y vernáculos que hace John B. Jackson.

El paisaje agavero no es un espacio homogéneo, más bien es una construcción social, histórica, asimétrica, con un centro, una periferia y una semiperiferia, donde se visibilizan y valoran ciertos artificios, invisibilizando otros.

(Paisaje agavero, tequila, patrimonio tangible e intangible)

\section{INTRODUCCIÓN}

1 documento discute cuatro concepciones relacionadas con el paisaje, el patrimonio y la agroindustria tequilera. Después de presentar ideas generales con respecto al paisaje agavero patrimonio de la humanidad, declarado como tal por la UNESCO en 2006, se presenta un somero recorrido histórico de los conceptos "paisaje" y "patrimonio", hasta mostrar cómo en la actualidad se encuentran vinculados en objetos materiales, mercancías o paisajes que, al mismo tiempo que se promueven como patrimonio, operan como mercancías, esto es, donde sobresale más la apreciación estética y su pragmatismo al ser utilizados para la

*yacatzushl@gmail.com 
promoción del turismo y, como consecuencia, como un factor de desarrollo económico en escala regional.

Ello da pie a cuestionar la visibilidad de ciertos artificios del paisaje y el fetichismo concomitante. Para entender la coexistencia de visibilidad de ciertas valorizaciones de un paisaje y la invisibilidad de otros paisajes culturales del agave y el tequila, se realiza un análisis desde la teoría del moderno sistema-mundo de Wallerstein, sugiriendo el hecho de que además de centro, semiperiferia y periferia, cada uno de estos espacios sociales se conforma o puede ser deconstruido a su vez en centro, periferia y semiperiferia.

El material empírico examinado para este artículo se recolectó de 2010 a 2012, luego de varios recorridos de campo por la comarca distinguida por la UNESCO como paisaje cultural patrimonio de la humanidad. La metodología se construyó con base en la propuesta de Wallerstein y del concepto de paisaje como una herramienta analítica para identificar centros donde se genera y acumula mayor valor, periferias que funcionan como fuentes de extracción de materias primas, espacios de exclusión, y una semiperiferia que permite los fenómenos de expansión y contracción de los centros de poder (Wallerstein 2005; Jackson 1984; Boehm 2001).

En los recorridos de campo se visitaron lugares turísticos, el primer cuadro de localidades, plantaciones de agave diversas, diferentes factorías y se entrevistó a jornaleros, agaveros y productores de tequila, con la finalidad de corroborar si era factible hablar de diversos paisajes, unos con alto contenido estético y otros relegados o que simplemente permanecen en la clandestinidad.

\section{El paisaje agavero}

El paisaje agavero, distinguido por la UNESCO en julio de 2006 como patrimonio cultural de la humanidad, representa un caso interesante para el análisis antropológico así como para otro tipo de cuestionamientos también de interés para las ciencias sociales, por ejemplo, la legitimación de un paisaje por una instancia superior a la nacional, o la fetichización del resultado de formas de organización y división del trabajo que configuran un paisaje. 
El reconocimiento al "paisaje agavero y a las antiguas instalaciones del tequila" se consiguió en la fecha indicada luego de años de trabajo por parte de organismos tomadores de decisiones de la industria tequilera, académicos y dependencias de los gobiernos federal y del estado de Jalisco.

Esa distinción abarca una porción de la geografía contenida dentro de la Denominación de Origen Tequila, ${ }^{1}$ comprendiendo territorio de los municipios de Tequila, Amatitán, El Arenal, Hostotipaquillo, Magdalena y Teuchitlán. El área total objeto de la distinción cubre 34,648 hectáreas comprendidas entre los valles y el volcán de Tequila y el cañón del río Santiago. El área de amortiguamiento está ubicada entre montańa y barranca con una superficie de 51,261 hectáreas.

Se trata de un paisaje viviente, de trabajo, de campos cultivados con agave azul, además de los centros históricos de los asentamientos urbanos, las destilerías en pie, pero también los vestigios de antiguas tabernas incrustadas en cascos de pequeñas haciendas o casonas coloniales, donde la bebida era producida. El área distinguida por la UNESCO incluye también las 360 hectáreas correspondientes al sitio arqueológico de Los Guachimontones, en Teuchitlán, por la ladera sur del volcán de Tequila.

Una de las metas por alcanzar con ese reconocimiento consiste en "propiciar la mejoría en la calidad de vida para la comunidad que habita en ella" (Gómez 2006,132). Lo anterior permite suponer que la conservación y la promoción del paisaje deberían detonar mejoras en la economía, la ecología, la educación, el aprecio y respeto a la tradición regionales. De hecho, entre los objetivos planteados por los promotores del paisaje como patrimonio descuellan aquellos que refieren a un interés por conservar e incluso mejorar las condiciones en las cuales se realiza el cultivo de agave, entendemos que por sus cultivadores. Lo anterior, para proteger sus formas y sus tradiciones cultu-

${ }^{1}$ Como se sabe, en 26 de los 32 estados de la República se fabrican destilados de agave. Para ello se utilizan 40 de las más de 150 agaváceas existentes en el país. Sin embargo, aunque por ley no está prohibido cultivar agave azul weber tequilana en ninguna parte del territorio nacional, la fabricación de tequila está restringida a una zona con denominación de origen comprendida por municipios de cinco estados. 
rales (véanse los objetivos en Gómez 2006), pero también puede decirse lo mismo de los vestigios históricos y arqueológicos.

En términos económicos, la promoción del paisaje agavero ha resultado exitosa como un nuevo destino turístico distinto a los de "sol y playa", donde se conjuga una producción agroindustrial peculiar como es la del tequila, con un escenario natural lleno de atractivos y de paisajes, entre los cuales descuella el sitio arqueológico de los Guachimontones, además del aire pintoresco que caracteriza a cientos de pequeños pueblos y localidades de México. A poco menos de 15 años de haber comenzado a recibir visitantes, el sitio arqueológico de Guachimontones es visitado por más de 100 mil personas al año; y según cifras recientes, la zona arqueológica, junto a La Ruta del Tequila, debido al programa de la Secretaría de Turismo "Tequila Pueblo Mágico" y a El Paisaje Agavero patrimonio de la humanidad, cerraron 2011 con una afluencia de visitantes mayor al medio millón de personas.

Muchos trabajos de investigadores han dado cuenta de la amenaza que representa para las zonas patrimonializadas la incontenible presencia de turistas y de viajeros. El deterioro ecológico y la alteración del orden social previo son fenómenos resultantes de las distinciones realizadas con nobles intenciones.

Antes de continuar con la exposición de datos conviene una reflexión a propósito de dos conceptos que se han vinculado en la teoría y en la práctica en la última década. Me refiero al "paisaje” y al "patrimonio".

\section{Sobre el paisaje}

Considero que son cuatro los enfoques teóricos, concepciones o usos pragmáticos de mayor relevancia para pensar el paisaje en la actualidad.

a) El paisaje como una creación artística

b) El paisaje como un objeto

c) El paisaje como una herramienta analítica

d) El paisaje como una mercancía 


\section{a) El paisaje como creación artística}

Esta concepción del paisaje aparece en Europa durante los siglos Xvi y XVII. ${ }^{2}$ Pintores y literatos fueron quienes en sus obras se encargaban de representar la naturaleza y de describir sus bellezas como paisajes.

Landschap, vocablo neerlandés del siglo XV cuyo significado es "trozo de país" designa la "porción de espacio delimitada por la ventana pictórica” (Roger 2008, 71). Un paisaje consistía en una representación del campo, del mundo rural, "valorizado y domesticado primero por la pintura flamenca y después por la italiana y también ensalzado por la literatura" (Roger 2008, 72). Con el tiempo, se incluirían como paisajes el mar y la montańa.

El paisajismo como fenómeno europeo de aquellos siglos no refería a lugares concretos o a la naturaleza en sí misma, sino al cuadro de la pintura, a la representación que los pintores hacían y plasmaban en un lienzo (Roger 2008, 76). Cierto es que había una imagen predominante, la del "país jardín" versus el país estéril, no colonizado ni integrado a la vida en la urbe.

En los siguientes siglos, el romanticismo y el impresionismo enriquecerían el acercamiento pictórico a la realidad contrastando estéticamente el pasado medieval y por ende rural, con el paisaje urbano e industrial. La pintura era la mensajera de esas emociones nostálgicas vueltas paisaje. ${ }^{3}$

\section{b) El paisaje como un objeto}

Humboldt fue un revolucionario al sintetizar dos tradiciones paisajistas; por una parte la explicativa y científica y, por otra, la com-

${ }^{2}$ Esto se debió, según apunta Roger, a que en esa época fue posible la laicización de los elementos naturales, al dejar de ser satélites de los íconos religiosos centrales, y por ende, a la posibilidad de que los elementos naturales formaran un grupo autónomo (Roger 2008, 70-31).

${ }^{3}$ De esa forma de conceptualizar el paisaje se destacan: la representación del campo o de la geografía por el arte; que el paisaje es un "punto de vista” con propósitos sensoriales o sentimentales y estéticos; que se trata de una "composición armónica-tanto en el territorio como en la tela- que pone orden al patrimonio nacional" (Minca 2008, 220), llegando al grado de convertirse en un instrumento para la indagación por la esencia de una nación, y que por tratarse de representaciones de la burguesía o del Estado conviene prolongar su permanencia en el tiempo, conferirles cierta sacralidad para volverlas inamovibles. 
prensiva o artística. Para Humboldt el conocimiento del paisaje debía considerar como punto de partida la visión directa del mismo, y acto seguido proceder a desentrańar la lógica interna de su aspecto externo o estructura así como a su comprensión valorativa. ${ }^{4}$

Considero el paisaje de Humboldt como objetualista, ya que para él el paisaje dejó de ser un asunto de apreciación estética, valorativa o un saber pictórico y también de corte poético. En su lugar, el paisaje fue un concepto científico útil para la descripción del mundo. Al considerar su movilidad o dinamicidad, Humboldt introdujo la idea de transformación de los paisajes y, con ello, abrió la puerta para el estudio de sus cambios inscritos en procesos sociales (véase Minca 2008, 215-221)..$^{5}$

La geografía francesa hizo algo similar al vincular los conceptos de paisaje y región al enfrentar problemas relacionados con cómo organizar administrativa y políticamente el territorio (Viqueira 2001, 17-30). Laplace, Le Play, Vidal de La Blache, entre otros, ordenaron el territorio bajo criterios naturales, por ejemplo, a partir de cuencas hidrológicas. El paisaje entendido como forma diferencial de la naturaleza pero con carácter estático y fijo a la mirada, hacía posible ese tipo de ordenamiento territorial; el relieve, la distribución orográfica, hidrológica y climática, eran las variables que servían para establecer medios homogéneos y, por ende, para delimitar administrativa y políticamente hasta dónde se encontraban las márgenes de las regiones. El observador y el factor antrópico quedaban fuera de foco o supeditados de manera determinista al medio; otro tipo de flujos de materia y energía eran desconocidos.

${ }^{4}$ Nicolás Ortega Cantero, Universidad Autónoma de Madrid. "Cómo pensar geográficamente el paisaje", Conferencia en el marco del taller "Pensar el paisaje”, El Colegio de Jalisco, 29 de noviembre de 2011.

${ }^{5}$ El vocablo alemán Landschaft significaba tanto barrio, distrito territorial o área delimitada, propiedad de un determinado seńor o habitado por un grupo humano particular (Broek 1938 en Houston 1970, 133), pero también la representación artística del barrio mismo (Farinelli 1992, 205 en Minca 2008, 216). Humboldt utilizó conscientemente el término en ese doble sentido, quedando en el fondo la acepción objetiva (Minca 2008, 216). El paisaje era un objeto específico del estudio geográfico cuya función era abordar la relación universal existente entre los diversos elementos del medio y su subordinación en el espacio (Humboldt 1991), era "la suma total de las características de una región de la superficie terrestre” (Humboldt 1849, 252 en Toledo 2006, 156). 


\section{c) El paisaje como una herramienta analitica}

En la segunda mitad del siglo xx surgió con fuerza la idea de pensar los paisajes como herramientas analíticas. En un extremo están quienes consideran que más que una descripción de la realidad es un concepto para acercarse a las relaciones materiales entre la cultura y la naturaleza; en la otra punta, quienes definen los paisajes como textos que pueden ser leídos previa descodificación.

En un borde ubico al geógrafo cultural Carl Sauer con su propuesta de paisajes culturales, como áreas geográficas resultantes de las diferentes asociaciones de formas físicas y culturales. Sobre los paisajes "prehumanos" formados y modelados por factores geográficos se realizan las actividades humanas y el resultado son los paisajes culturales. El centro o principal factor morfológico lo constituyen los seres humanos y sus formas de apropiación del paisaje natural (Sauer 1925, 343). Hay un proceso de construcción de la realidad por las sociedades humanas a partir de su interrelación con la materia existente. ${ }^{6}$

Los paisajes constituían un todo indivisible: "El paisaje cultural se crea, por un grupo cultural, a partir de un paisaje natural. La cultura es el agente, el área natural es el medio, y el paisaje cultural el resultado" (Sauer 1925, 46). Por cultura entendía "la huella de los trabajos del hombre sobre un área" (Sauer 1925, 38). Tres factores eran básicos para el estudio del paisaje: "el entorno físico, el talante de la gente y el tiempo" (Norton 1989, 37). El paisaje era un área objetiva pero ya no aludía a una escena o vista concreta.

Su propuesta involucra una combinación de tiempo y espacio, además de aquello que significa la historia, a saber, que son procesos contingentes, debido a lo específico de las fuerzas humanas que los

6 "Cada población humana, en distintas etapas de su historia, ha necesitado evaluar el potencial económico del lugar donde habita para organizar su vida con lo que el ambiente le ofrece en términos de los conocimientos de que dispone y de sus valores. En esta valoración cultural de su medio ambiente, desencadena una deformación de sus paisajes prístinos o prehumanos, a medida que incrementa la magnitud de la ocupación por el aumento de la población y de sus conocimientos. El estudio de los paisajes culturales se propone, por tanto, comprender el proceso de la apropiación, hábitat por hábitat, resultante de la expansión de las diferentes culturas humanas en todo el oikoumene" (Sauer $1956,1)$. 
modificaron. Cada paisaje es único, no obstante, está relacionado con otros paisajes presentes y pasados. ${ }^{7}$

En Sauer hay un distanciamiento de la simple descripción o inspección ocular y de su correlato, a saber, la exploración con fines colonialistas; el interés está puesto en el estudio de las sociedades pasadas mediante el estudio de las áreas o espacios transformados para entender su forma de vida, la forma como organizaban el espacio y los artificios culturales con los cuales lo transformaron. ${ }^{8}$

En el otro borde ubico a los semiólogos, quienes consideran que los paisajes son textos, imágenes, dinámicos códigos de símbolos que hablan de la cultura de una sociedad, de su pasado, pero también de su presente y de su futuro y, para comprenderlo, es preciso descodificar cada uno de esos textos identificando el sistema de signos que lo componen y lo configuran. Cada elemento tiene un significado propio y está en relación con los demás mediante una sintaxis hasta producir un texto legible (Busquets 2009, 151).

John B. Jackson resulta relevante para las ciencias sociales por su interés tanto por los aspectos simbólico e ideológico, como el material de los paisajes a través de la inclusión del concepto de relaciones de poder en la definición de distintas clases de paisajes. Cada paisaje es una "colección de espacios construidos por un grupo de gente [con pretensiones específicas y desde su cultura] para crear un orden y para producir [...] una sociedad" (Jackson 1995, 43).

El paisaje tiene una función cultural al ser fuente y repositorio de significados simbólicos y valores, pero esa función se complementa con un análisis crítico de las relaciones de poder al cuestionarse por

${ }^{7}$ Acto seguido podrían establecerse regiones culturales homogéneas definidas con base en elementos materiales (cerámica, material de construcción o tipos de vivienda), tanto como a partir de elementos culturales (religión, lenguas y dialectos). El último paso propuesto consistía en el estudio de la ecología cultural histórica con énfasis en cómo la percepción y el uso humano del paisaje estaban condicionadas por elementos naturales (Luna 1999, 72).

${ }^{8}$ La Nueva Geografía Cultural de tradición saueriana sostiene que el paisaje "es una construcción ideológica, caracterizada por precisas coordenadas culturales y objetivos políticos" (Minca 2008, 221), no existiendo en consecuencia la objetividad que se difunde al describir los paisajes. Por ello es que hay ciertos elementos del paisaje cultural que se vuelven visibles mientras otros se ocultan. Otro aspecto relevante consiste en que además del espacio geográfico, el tiempo también es una construcción ideológica. 
los constructores y las formas de construcción de esos paisajes que deben distinguirse según si son vernáculos o políticos. Nunca habrá paisajes naturales, siempre el paisaje, en términos heurísticos, será un palimpsesto. ${ }^{9}$ Un paisaje vernáculo consiste en

un arreglo de sitios con poca coordinación, con poco orden aparte de consideraciones fundamentales como el acceso al agua, tierras fértiles y yacimientos de materiales básicos. En casos extremos hay igualdad en esa distribución. Se trata de un paisaje autoformado usualmente de manera gradual desde abajo, es un artefacto del pueblo (Weigand 2007).

\section{por el contrario, el paisaje político muestra}

un arreglo de sitios con jerarquía definida, acceso diferencial al agua y a las mejores tierras, a los yacimientos [...] Hay diferentes niveles de sitios basados en funciones diferentes, o en otras palabras sitios especializados y diversificados: sitios ceremoniales, de administración, fortificaciones, centros de barrio, talleres, centros de minería, habitaciones humildes, habitaciones estilo palacio, campos de cultivo especializados e intensificaciones como chinampas, etcétera (Weigand 2007).

Este paisaje, en contraste con el anterior, se forma "desde la cúpula social del sistema” (Weigand 2007). Muchas veces los paisajes políticos se construyeron sobre los vernáculos. En términos analíticos uno no puede ver sólo los paisajes vernáculos sin observar los centros de poder, geométrica y proporcionalmente construidos, simétricos y balanceados, monumentales y dominantes, esto es, los paisajes políticos que los absorben, circundan o articulan. Por ende, la propuesta de Jackson implica una lectura del paisaje cultural en escala regional.

${ }^{9}$ Refiere a un documento que conserva huellas de los diversos escritores en diferentes periodos históricos, con sus peculiares escrituras y estilos o técnicas del pasado. Figurativamente indica que en un paisaje intensamente ocupado por seres humanos pueden rastrearse e interpretarse huellas de varios periodos históricos y diferentes formas de hacer uso de los recursos y ocupación del espacio. 
Jackson analiza tanto la configuración del espacio como del tiempo al sostener que los paisajes son deliberadamente creados para "acelerar o ralentizar los procesos naturales". ${ }^{10}$ La historia viene a ser un sustituto de esos fenómenos naturales de crecer-madurarreproducir-morir (Jackson 1984, 156).

En un paisaje pueden encontrarse de manera simultánea "las formas en las cuales circulan materia y energía en el tiempo y en el espacio, así como las formas como se mantienen y dispersan los organismos, y como se sostienen y reproducen las sociedades humanas a través de los usos de suelo y de sus ideologías" (Brandt y Vejre en Toledo 2006, 157).

Para explicar los procesos adaptativos en la ribera norte del lago de Chapala, Boehm también utilizó el concepto de paisaje como una herramienta analítica. Para ella, el paisaje es el resultado de la conjugación de una diversidad de artificios; en él están presentes múltiples escritores a través de sus escrituras, hechas en distintos tiempos y, en ocasiones, de manera simultánea y contradictoria. La identificación de los artificios visibles en un paisaje constituía la primera dimensión analítica de la metodología de la lectura del paisaje cultural acuñada por ella e implicaba necesariamente un esfuerzo por involucrar diversas disciplinas que permitieran la construcción de una robusta herramienta para analizar cómo:

las manifestaciones y las huellas visuales del artificio humano conforman escrituras impresas en el espacio geográfico, a cuya lectura se exponen cotidianamente los habitantes de una región. El desciframiento de los signos escritos por los diversos grupos subculturales en distintos tiempos y con diferentes caligrafías conduce a la internalización de los significados de los lenguajes que, entonces, revelan las diferencias socioculturales y las expresiones geográficas de inclusión y exclusión (Boehm 2001, 59).

La segunda dimensión analítica de la metodología boehmiana es la lectura de la organización social y la cultura subyacente a los artificios. Es necesario indagar por los autores de los artificios, por

${ }^{10} \mathrm{Al}$ respecto véase también Galí-Izard, 2005 y Martignoni, 2008. 
aquellos que los controlan y por los excluidos, por las intenciones con las que fueron construidos, etcétera (Boehm y Sandoval 1999 y Jackson 1984, XI-XII, 3, 14 y 15).

Una tercera dimensión de análisis implica la consideración de los contenidos simbólicos presentes en las obras materiales, así como las influencias ideológicas que permiten explicar determinados diseńos arquitectónicos, la presencia de una cruz o una imagen religiosa en una obra hidráulica, lo cual se complementa con la dimensión de la percepción, "del impacto visual que ejerce [ese símbolo] sobre los habitantes del espacio transformado" (Boehm 2006, 183).

\section{d) El paisaje como una mercancía}

En la actualidad se encuentra un menor interés científico por el estudio de los paisajes; sin embargo, las políticas encaminadas a construir, diseñar, gestionar, conservar paisajes y ordenar el territorio con relación a los paisajes no tienen precedentes (Jellicoe 2004; Zoido 2006; Martignoni 2008). Hay mayor pragmatismo que teoría.

Tanto en Europa como en Asia hay convenciones internacionales dedicadas a los aspectos forestales, ecológicos y sustentables de los paisajes. Como trasfondo de este interés por construir y preservar "espacios naturales" o poner en valor prácticas culturales ligadas a ciertas formas de usar espacios geográficos, lo mismo se encuentra una preocupación por frenar los intensos y extensos procesos de degradación ecológica o componente territorial, de desertificación y de crecimiento de las manchas urbanas a través de incentivar la participación ciudadana (Zoido, 2006, 71-72 y 85), que una preocupación estética y mercantil, donde una desbordante carga simbólica asociada a paisajes hasta hace poco invisibles para las miradas estatal y de la iniciativa privada, han adquirido una relevancia que supera con mucho las potencialidades reales de la comarca. El componente perceptivo cobra mayor valor que el elemento real debido a su fácil mutabilidad en capital económico.

No obstante, en ciertos escenarios, los análisis y los discursos políticos demuestran una preocupación genuina por proteger ciertos paisajes como elementos importantes en la calidad de vida de las personas, y por eso se les concibe como patrimonio natural y cultu- 
ral de las poblaciones. Por ello deben controlarse los procesos urbanizadores, la indiscriminada expansión de agroindustrias y la invasión de contaminantes urbanos (Zoido 2006, 95-99; Vigna 2006). Una estrategia política para garantizar su conservación en el tiempo consiste en declararlos bienes patrimoniales.

\section{Sobre EL PATRIMONio}

El concepto de patrimonio también ha cambiado en su devenir histórico. Mientras el paisaje transitó de representación a "cosa" para luego ser movilizado como una mercancía, el concepto de patrimonio pasó de ser un repositorio o acervo para adoptar una forma más elástica ampliando sus alcances al grado de considerar como bien patrimonial ciertas expresiones intangibles y paisajes, cuyas características son su vitalidad o el hecho de no requerir repositorios para su almacenamiento o exhibición. Empero, al contar con un sello distintivo esos bienes se promueven como símbolos que contribuyen a la formación de una identidad cultural. Sin embargo, en la actualidad, al igual que el paisaje, la conceptualización del patrimonio funciona como mercancía generadora de capital. ${ }^{11}$

Fue en el siglo XIX con la formación de los Estados nacionales en América Latina con la independencia política y económica de Espańa cuando comenzó a hablarse de patrimonio cultural de una nación, ${ }^{12}$ constituido éste por valores históricos y culturales identi-

${ }^{11}$ A propósito del proceso de inclusión de la cultura inmaterial como patrimonio intangible véase Arizpe, 2009. Los orígenes del concepto se remontan al derecho romano y al código civil francés (Figueroa 1995, 28). Patrimonium era la hacienda que una persona heredaba de sus ascendientes, y se refería a la propiedad absoluta, exclusiva y a perpetuidad de cosas o bienes (Gutiérrez 2002, 42 y 197), además de ser un atributo de la libertad individual. El concepto comprendía la idea de propiedad, pero también la de obligación, sobre todo en caso de deudas (Figueroa 1995, 23-29). Diríase que de manera exclusiva estaba asociado con la riqueza pecuniaria de una persona. Por ello se atesoraba (metales, joyas) aquello que podía convertirse en valor económico; obras de arte y ciertos trofeos eran sólo considerados exóticos y su valor era simbólico. Al ser más importante el valor económico que el estético no importaba conservar las manifestaciones culturales de los vencidos. Había en el fondo una postura etnocéntrica y obviamente intolerante (Llull 2005, 182).

${ }^{12}$ A partir de la Revolución Francesa se introdujo la idea de patrimonio nacional bajo la protección estatal, "frente a los monumentos erigidos a la soberbia, a los prejui- 
ficados con "lo propio" versus "lo ultramarino". ${ }^{13}$ Una valorización de tal envergadura se centró sobre todo en cultura material (arqueológica e histórica, en su mayoría arquitectónica y escultórica, y obviamente representativa de los grupos dominantes) cuya contribución en la formación de una identidad nacional era relevante en términos simbólicos. Esto coincide con la definición de patrimonio de Llorenç Prats, quien sostiene que es "su carácter simbólico, su capacidad para representar simbólicamente una identidad" el factor determinante para la existencia del patrimonio como tal (Prats 1997, 22).

Esa concepción de patrimonio cumplía dos funciones principales en un Estado nacional: hacia afuera funcionaba para reivindicar valores propios, mientras que hacia el interior servía para proyectar identidades políticamente aceptadas o convenientes (Florescano 1993, 10). La reivindicación de un pasado común, la comunidad de lengua, cultura y valores, y una pretendida unidad e identidad transhistórica, han sido desde entonces parte de los discursos fundantes de las nacionalidades y de su interés por conservar su patrimonio cultural histórico (Pérez-Ruiz 1998a, 95). Cada nación contaba con un patrimonio económico, pero también otro definido por su valor cultural, independientemente de su fungibilidad. Ambos tenían además un valor simbólico debido a su función de generadores de una identidad cultural (CINU 2002).

En el contexto actual, el concepto abarca también los bienes intangibles o expresiones culturales (pensamientos, ideas, música, danza, usos, representaciones) junto a los bienes materiales (arquitectura, arqueología, artesanía, arte), tanto de propiedad individual

cios, a la tiranía” (Melé 1998, 12). Una idea subyacente a la incorporación del discurso del patrimonio en las legislaciones obedece a la forma en la cual era utilizado, por ejemplo, en los monumentos históricos, con valor didáctico, por ser el soporte del conocimiento histórico; valor estético, por tratarse de objetos de disfrute universal; valor nacionalista, por ser íconos de los sentimientos nacionales (Melé 1998, 12).

${ }^{13}$ En la introducción al libro, Florescano señala que política e ideológicamente los Estados nacionales destruyeron el monopolio cultural metropolitano y, al mismo tiempo, abrieron la puerta a valorizaciones propias en diferentes escalas, a través de la fundación de instituciones cuya función era crear la identidad de una nueva nación (Florescano 1993, 9-11). 
como aquellos otros colectivos (Florescano, 1997a, 9; Tovar y de Teresa, 1997a, 96); y desde el año 2000 el "entorno natural" y ciertos paisajes han pasado a ser expresiones del patrimonio cultural ya no sólo de un Estado-nación, sino incluso de la humanidad. Organismos internacionales como la UNESCO promueven y apoyan programas de rescate, de conservación y/o de preservación de determinados bienes o expresiones culturales ubicados en diferentes latitudes, al margen, con la venia o por encima de los Estados nacionales, además, de acuerdo con "criterios esencialmente occidentales" (Bonfil 1997, 32). En el contexto actual puede importar más la valorización intencional que la legitimación otorgada por los Estados (Melé 1998, 11).

\section{El Fetichismo de los PAisajes}

Una característica de la primacía de la actual "puesta en valor" de paisajes y patrimonios es que se crean valores simbólicos, lo que Baudrillard ha denominado "valor signo" (1974), y que yo he denominado "estetización" (Hernández 2007). Lo anterior puede expresarse desde la teoría clásica marxista como una acentuación del valor de cambio y un desprecio del valor de uso. Se sabe mucho de la planta de agave y del tequila, pero no se dice ni se sabe quiénes son los cultivadores, cómo están organizados o porqué hay plantaciones con extensiones superiores a 100 hectáreas mientras hay otras menores a una hectárea. Unas tienen caminos, están cercadas, tienen riego por goteo y mantenimiento constante mientras que otras están en pedregales y entreveran cultivo de maíz, frijol, calabaza, cacahuate o garbanzo.

Es decir, ciertos fenómenos de los procesos históricos y sociales son invisibles o son ocultados. Una mirada desde las relaciones de poder sugiere que un paisaje en realidad es un conjunto de paisajes, vernáculos y políticos, que se complementan, contrastan o se encuentran en clara ruptura. Hay paisajes antiecológicos en los cuales la fuerza de trabajo realiza sus actividades en condiciones tradicionales de explotación; al lado de esas expresiones hay otros pequeños paisajes donde sus creadores se preocupan por conservar la tierra, 
por combinar cultivos, donde parece existir mayor conciencia ecológica y el desgaste humano es menor debido a la forma como se conceptualiza el cultivo: es una alcancía antes que ser una mercancía.

El valor de uso, es decir, la puesta en valor de la forma de construcción de un paisaje es importante en momentos en los cuales la contemplación, las industrias simbólicas y turísticas dirigen la mirada en otra dirección.

En los tours por el paisaje agavero, o simplemente en las plantaciones agaveras vinculadas con alguna industria, es obligada la visita para ver trabajar a los jimadores. Uno de los efectos de verdad, para aludir al concepto de la historiadora Ana María Alonso (1988), consiste en visibilizar al jimador como el vínculo entre el crecimiento cuasi natural del agave, es decir, como una planta semidesértica y los procesos industriales. La vulnerabilidad y el ocultamiento de las condiciones de vida de los jornaleros son reales. Así, la imagen del jimador (significado) no corresponde con la realidad de los jimadores de carne y hueso (significantes). Más allá de la propia percepción de los sujetos, la desacreditación y la pérdida de valor de los conocimientos tradicionales frente a las tendencias modernizadoras son los fenómenos que permiten identificar esas condiciones de vida.

A ello me refiero cuando sostengo que al mismo tiempo que se "agrega valor" o "se pone en valor" la producción de agave que configura paisajes peculiares, se ocultan otros paisajes vernáculos donde se conservan o reproducen los saberes artesanales del México profundo.

\section{LA HETEROGENEIDAD DE PAISAJES}

Sugiero pensar el paisaje agavero en términos heurísticos como un pequeño sistema-mundo dentro del moderno sistema-mundo propuesto por Wallerstein. Esto porque como antes indiqué, el paisaje está compuesto de múltiples artificios que constituyen distintos paisajes, algunos vernáculos y otros políticos. Hay artificios que corresponden a uno u otro de los extremos. En términos heurísticos el paisaje agavero está constituido por zonas centrales, con mayor inversión y potencial generador de riqueza, zonas periféricas excluidas de tales beneficios y zonas intermedias o semiperiféricas. 
De acuerdo con Wallerstein un sistema-mundo se constituye como tal no por abarcar la totalidad del mundo, sino por estar conformado como una unidad. Lo que vincula las partes es el factor económico, reforzado por las dimensiones política y cultural (véase Wallerstein 1998, 21). Un sistema-mundo es ante todo un sistema social, caracterizado por fronteras establecidas entre los diferentes componentes o nodos, con estructuras, instituciones, reglas y formas de relación y cierta coherencia (Wallerstein 1998, 489), esto es, un factor dinámico en su conformación lo constituye la presencia de fuerzas en continuo conflicto.

Gráfica I. Modelo de sistema-mundo de Wallerstein

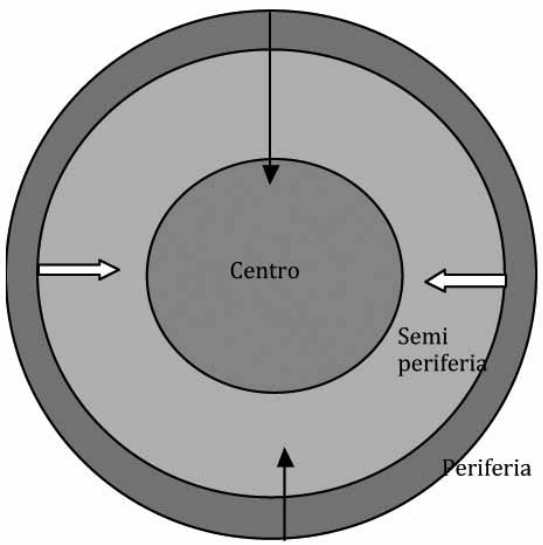

Fuente: Elaboración propia.

Si se procede desde lo macro del sistema-mundo capitalista teorizado por Wallerstein diríase que el tequila no es el centro del sistema y más bien su historia ha sido periférica. En el mundo de las bebidas alcohólicas el whisky, el cognac y ciertos vinos de uva han sido centrales. Sin embargo, a raíz de las inversiones de empresas transnacionales, de la participación del Estado mexicano como defensor y promotor de la bebida nacional, y de la consolidación del tequila como un producto con Denominación de Origen, a los cuales se suma la declaratoria del paisaje agavero como patrimonio cul- 
tural de la humanidad como parte de la modernización del tequila, podemos establecer que esta región se ha movido hacia la semiperiferia del sistema-mundo capitalista producto de una expansión (Wallerstein 2005, 12) ${ }^{14}$ de los centros económicos para abarcar otras bebidas alcohólicas o para generar ganancia económica de otras latitudes.

Considero que la adopción de este esquema analítico ayuda a entender por qué en el paisaje agavero se presenta el fenómeno de expulsión hacia la periferia de los agentes que con su trabajo son artífices de muchos de los vistosos paisajes, pero también una exclusión de los saberes artesanales, mientras en el centro se legitiman las modernas tecnologías para la elaboración del destilado y se construyen personajes emergentes como símbolos de una industria, es el caso del jimador inexistente hace treinta años como 1) jornalero, 2) especializado en una actividad única, 3) distinguido con un fuerte agregado de concepciones estéticas con respecto al trabajo desempeñado. Antes simplemente existían campesinos o peones quienes realizaban la diversidad de tareas requeridas en los campos.

El paisaje agavero es un mundo de traslapes, por ejemplo, entre técnicas de cultivo rústicas o vernáculas, con otras que son producto de nuevas racionalidades y se caracterizan por el uso de nuevas tecnologías, sin embargo, permea la idea de homogeneidad, de inexistencia de un sistema asimétrico. Por ello, lo que en el centro de este paisaje se presenta como real e histórico constituye una de las expresiones del triunfo del paisaje, del patrimonio como mercancías y de la cultura como medio de entretenimiento (Rinaudo 2011, 56).

Por ello, el centro de este sistema-mundo coincide con las zonas donde se encuentran instaladas las industrias destiladoras de mayor peso en el ramo, así como los campos agaveros que las circundan y que están controlados por ciertos actores; obviamente entre esos predios se incluye El paisaje agavero patrimonio cultural de la huma-

${ }^{14}$ De acuerdo con Wallerstein, "regiones particulares del mundo pueden cambiar su papel estructural en la economía-mundo" sea en beneficio propio o movidos por un impulso exterior, empero de manera simultánea aumenta la disparidad de beneficios entre los diferentes sectores de la economía-mundo en su conjunto (Wallerstein 1998, 493) y también al interior de las regiones. 
nidad y las antiguas instalaciones industriales del tequila distinguido por la UNESCO como patrimonio cultural de la humanidad desde $2006 ;^{15}$ se añaden a ese céntrico espacio social los primeros cuadros de los poblados convertidos también en zonas remozadas con fines de atracción turística. El factor geográfico es importante, pero el control sobre esos espacios es lo realmente relevante a la hora considerar una zona como centro del sistema.

La periferia está conformada por las zonas cercanas o lejanas, en términos geográficos, incluidas dentro de la Denominación de Origen Tequila, pero en las cuales por diferentes factores las condiciones para el establecimiento de plantaciones o de industrias son poco favorables, por ejemplo, por la inexistencia de fuentes de agua o por su cercanía con el mar; por tratarse de zonas lacustres o de la cima de una montańa; por la presencia de productores de enervantes, o por constituir el centro de otra actividad socioeconómica, etcétera. Forman parte de esta periferia quienes elaboran tequila con formas artesanales, incapaces de modernizarse debido a sus limitados recursos económicos para la compra de tecnologías y para el pago de membresías, impuestos y registros ante el gobierno y las instancias oficiales de la industria tequilera; además de no contar con canales para la comercialización de sus productos de tal suerte que puedan recuperar la inversión en un corto plazo. Así, apartados o imposibilitados para sumarse a la corriente exitosa del tequila, aunque en algunos casos también como una estrategia, y esto es importante destacarlo, algunos propietarios de tabernas ${ }^{16}$ se reproducen en tiempos de aumento en los precios del tequila como productores clandestinos e informales con capacidad de abasto microrregional, haciendo uso de las redes sociales de carácter moral y consanguíneo. Mientras el centro se define por el agregado estético como vía para la construcción de una nueva imagen del tequila y para la generación de ganan-

${ }^{15} \mathrm{El}$ paisaje agavero es centro por generar riqueza como zona de producción de agave, pero también como destino turístico.

${ }^{16}$ Taberna tiene un significado regional correspondiente a "clandestino", mientras "tequilero", "industria" y "fábrica" remiten a un fabricante establecido legalmente y registrado en la Cámara Nacional de la Industria del Tequila y/o en el Consejo Regulador del Tequila. 
cias; en la periferia, la clandestinidad es a la vez resultado de la existencia del centro y una estrategia para distinguir los productos artesanales y sus paisajes vernáculos.

La semiperiferia está constituida por zonas donde es posible la expansión de la agroindustria tequilera, dentro y fuera de la Denominación de Origen, esto debido a que su crecimiento o contracción siempre está motivada por intereses económicos. Este espacio social es controlado de dos maneras por algunos cuantos productores de agave o intermediarios culturales o por algunos industriales tequileros. El primer mecanismo se da mediante la expansión directa del centro; el segundo a través del fortalecimiento de "coyotes" al interior de la semiperiferia, los cuales articulan pequeños productores hacia dentro y establecen el vínculo con los productores del centro.

Como se desprende del modelo, centro, periferia y semiperiferia son construcciones históricas, son formas de relación motivadas por intereses económicos y políticos y, en ciertas condiciones, limitadas por la geografía. No obstante, el sistema está en constante movimiento y experimenta cambios debidos a su propia dinámica y a la del sistema mayor del cual forman parte.

GráfICA 2. La propuesta de pensar el paisaje como un sistema-mundo. El modelo indica que el paisaje sistema-mundo -enmarcado- forma parte de un sistema-mundo mayor. Pero que a su vez puede subdividirse en centro, periferia y semiperiferia.

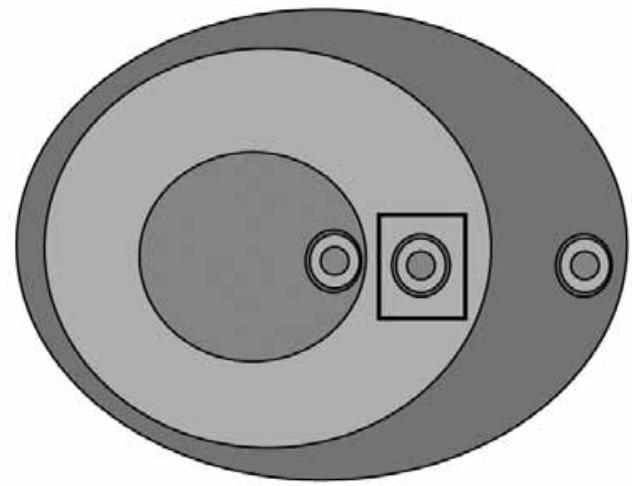

Fuente: Elaboración propia. 
Consecuencia de esta conformación de los paisajes es que podamos distinguir paisajes políticos y paisajes vernáculos. Para los fines de esta argumentación consideremos que, como se dijo antes, el centro del paisaje agavero como sistema-mundo es Tequila y sus alrededores.

Cuando se visita la zona arqueológica de los Guachimontones o se viaja del otro lado del río Santiago, al norte de Tequila, se encuentran manifestaciones arqueológicas, históricas y contemporáneas de diferentes grupos humanos, se está en el centro del sistema, donde la generación de valor, el alto contenido de estética, la construcción del patrimonio y el paisaje como mercancía y el uso de la cultura a partir de múltiples expresiones funciona como un medio de entretenimiento, como ha apuntado también Rinaudo (2011).

Una placa colocada por los responsables del Plan de Manejo del Paisaje Agavero en un horno de mampostería de la sierra tequilense colindante con Zacatecas reza más o menos así: "Taberna tradicional, vestigio y antecedente de la actual forma de producción de tequila”. El que la placa haya sido colocada por los responsables del mantenimiento del paisaje cultural resulta relevante, porque la taberna se encuentra fuera de la zona que se delimitó para ser distinguida como patrimonial por la UNESCO, lo anterior aun cuando las evidencias históricas sugieren la imposibilidad de desarticular la sierra de Zacatecas de la barranca del río Santiago, el volcán, el valle y la sierra de Tequila, ya que la tradición mezcalera en esa comarca es más amplia y con más interconexiones que la delimitada por los responsables a partir de considerar los valles de Tequila como centrales, sólo amortiguados por la barranca al norte y por el volcán al sur. Es decir, además de excluir la taberna del perímetro considerado como digno de patrimonialización, el proceso de elaboración de tequila que ahí se lleva a cabo también se descalifica al relegarlo a vestigio y antecedente de la moderna industria tequilera. Lo anterior constituye una de las formas de construcción de periferias y clandestinidad.

Que formas artesanales como la de la taberna de marras tengan estatus de clandestinas y periféricas significa por una parte, una situación de vulnerabilidad, un riesgo que apunta hacia la desapari- 
ción de ciertos paisajes y patrimonios culturales valiosos, puesto que sus artífices al no encontrar oportunidades para su reproducción en el cultivo de agave y no poder producir tequila porque sus conocimientos y prácticas son considerados inferiores -con lo cual se pretende que el consumidor vincule de manera inconsciente esa bebida con "producto de menor calidad"-, migrarán a otras actividades socioeconómicas; empero, esa condición de clandestinaje también representa una vía para que los pequeños productores se desvinculen de las modernas formas de producir tequila y de sus cosméticos paisajes.

La clandestinidad casi siempre es sinónimo de estar: 1) al margen de la ley y 2) al margen de quienes tienen el control en la industria tequilera, pero en muchos casos ser periférico y a su vez clandestino en lugar de significar mínima calidad en la bebida elaborada y un riesgo para la salud o adulteración, más bien se traduce en bebidas genuinas, producidas en pequeńos volúmenes, por productores que tienen control sobre el proceso de cultivo del agave, que seleccionan aquellos ejemplares que están en condiciones de ser aprovechados y cuya destilación es realizada a partir de la observación del comportamiento del agave en cada fase del proceso: si el agave está bien cocido, si está listo para fermentar o si esta fase concluyó, la temperatura a la que se encuentra, el clima atmosférico y las condiciones para destilar, etcétera. Es decir, en la periferia se abren nuevas vías para comerciar tequilas genuinos al margen de los grandes intereses y de los canales estatales, en algunos casos con los agregados de valor que representan el comercio justo y la sustentabilidad ambiental. ${ }^{17}$

Esa taberna catalogada por el comité del Paisaje agavero patrimonio de la humanidad como tradicional, en realidad contemporánea, se construyó justo en 2002, en la coyuntura de la última alza de precio del agave. Edificada a la usanza tradicional, la taberna utiliza materiales del entorno, los cuales son más asequibles al bolsillo del fabricante. De ahí su carácter vernáculo, aunque para nada es un vestigio. El problema de esa visión evolucionista por extensión apli-

${ }^{17}$ Un caso exitoso de productores artesanales que desde la clandestinidad van emergiendo es el de los productores guerrerenses Sansekan tinemi, con los cuales ha venido trabajando Catarina Illsley (Illsley 2008). 
Fото г. Taberna "a cielo abierto" ubicada al norte de la localidad de Tequila, en la Sierra Madre Occidental, colindante con Zacatecas. Fragmento de un paisaje agavero vernáculo o periférico.

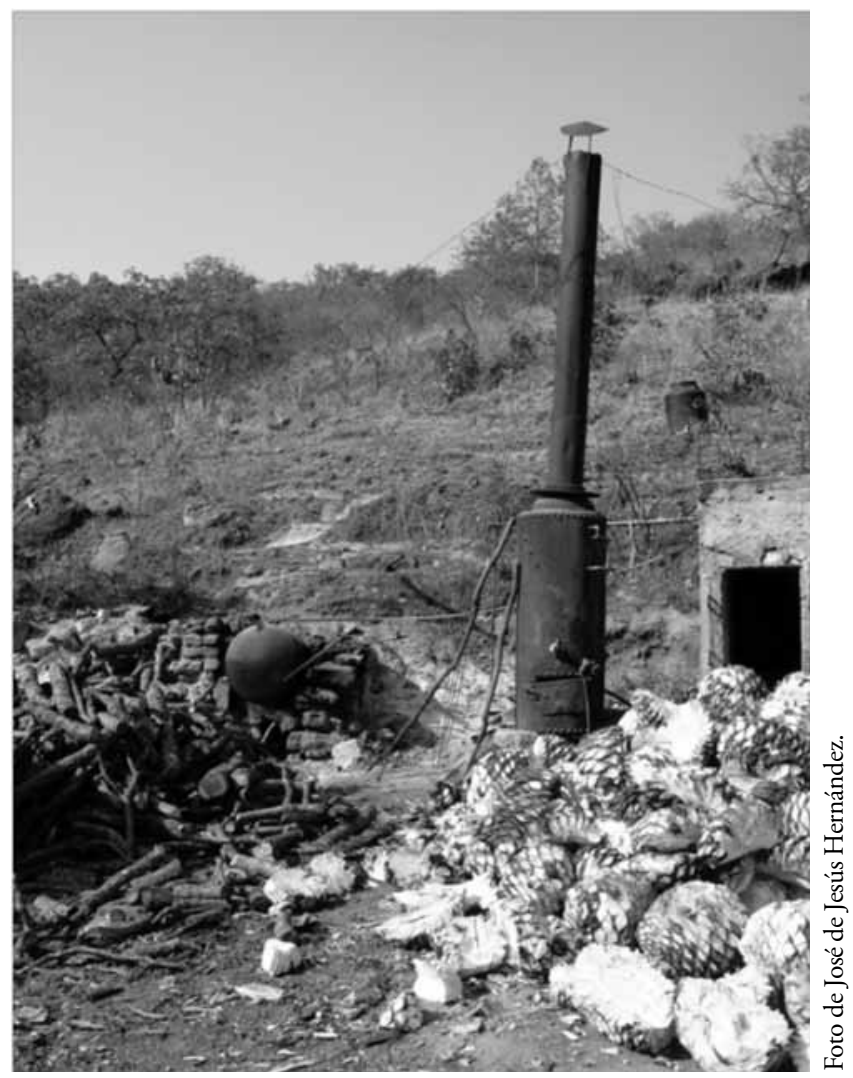

cable a todo el paisaje agavero es que legitima ciertas formas de producción y a ciertos creadores; así como "pone en valor" y "aprecia" algo, también "desvalora" y "de[s]precia" algo. Un tequila de calidad se identifica por las etiquetas de la botella, con las cuales el Estado da fe que se han pagado impuestos y el Consejo Regulador del Tequila garantiza que se verificaron las fases del proceso químico, aun cuando tales instancias sean incapaces de saber las características del aga- 
Foто 2. Taberna en establo lechero. Sierra de Tequila. Expresión de un paisaje vernáculo.

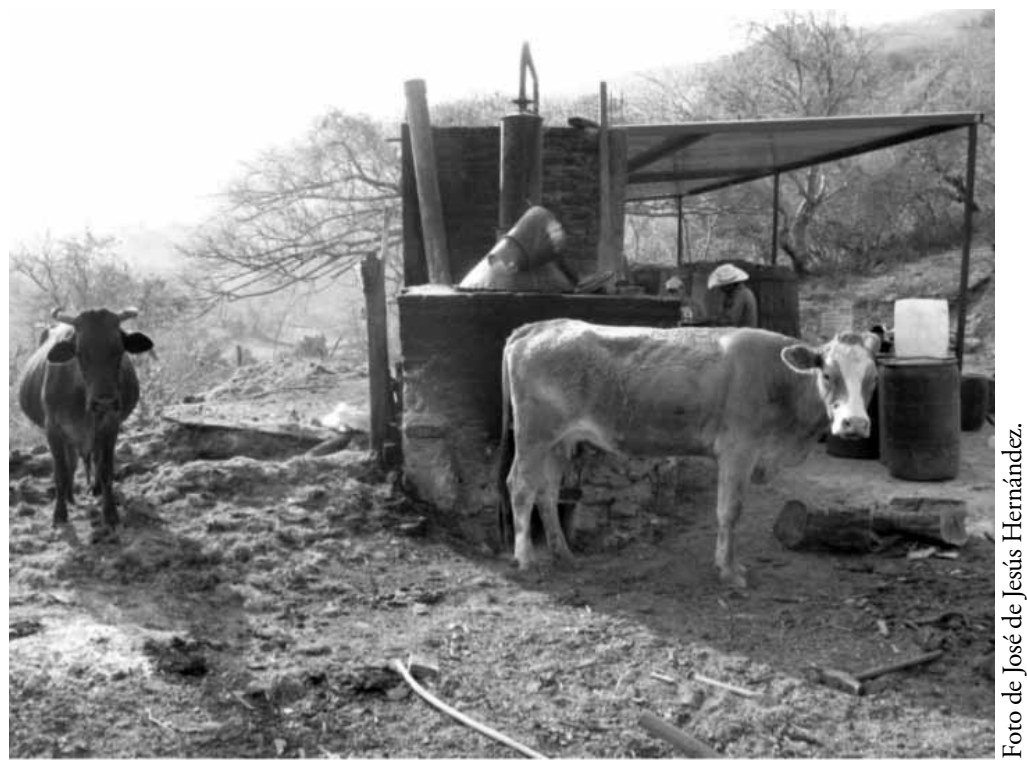

ve. Luego entonces, un paisaje mirado desde otra perspectiva exhibe asimetrías políticas y sociales. Los destilados de aquellas tabernas, vestigios del pasado -se dice-son de dudosa procedencia porque no cumplen con los requisitos establecidos por la normatividad oficial mexicana y por quienes tienen el control de la industria. Se trata de la configuración de un paisaje político, un paisaje de poder.

En 1999, los Guachimontones recibieron mil visitantes, pero diez años más tarde, en 2009, recibieron 100 mil; dos años más tarde, en 2011, todas estas figuras turísticas, a saber, los Guachimontones, la Ruta del Tequila, Tequila Pueblo Mágico y el Paisaje Agavero cerraron con medio millón de visitantes, casi 1,500 visitantes por día. Así, mientras los reflectores se dirigen hacia unos cuantos artificios del paisaje generando importantes ingresos económicos que no se distribuyen socialmente, en los márgenes de este paisaje sistema-mundo, se reciben otros visitantes interesados por el genuino carácter del tequila, y los productores vernáculos van fortalecien- 
do los lazos de sangre y de amistad para la distribución de su producto, que como se mencionó antes, no por circular fuera del mercado y de la vigilancia del Estado son un riesgo para la salud.

Fenómenos acontecidos en el centro o en la semiperiferia tienen repercusiones diversas en la periferia, ahí los productores artesanales buscan aprovecharlos a fin de no quedar excluidos. Por ejemplo, la caída del precio del agave hasta unos centavos por kilogramo golpeó a muchos pequeños productores, máxime cuando algunas de las grandes fábricas se han vuelto autosuficientes en el abasto de agave. Ello posibilitó el salto de pequeños agaveros a fabricantes de tequilas clandestinos, que poco a poco están dejando su huella en el paisaje.

\section{Conclusión}

Concluimos con la pregunta ¿¿desde qué concepción debe entenderse el paisaje agavero? Desde nuestro punto de vista es claro que el paisaje cultural del agave no refiere a una creación artística o pictórica. Tampoco alude a un concepto científico similar al utilizado por Humboldt, ni en estricto sentido a un objeto geográfico, en todo caso sería a la imagen percibida de un cultivo peculiar. Para escudriñar bajo qué concepción debe entenderse ese paisaje hemos recurrido a la propuesta de Boehm y de Jackson para pensarlo como una herramienta analítica, a fin de entender cómo en el caso particular, más allá de una definición, lo que existe es una pragmática identificación entre paisaje y mercancía o atractivo turístico. De hecho, lo mismo sucede con el concepto de patrimonio, el cual deja de hacer referencia a un símbolo factor de identidad para convertirse en una estrategia de marketing, como Ávila, Pérez y Rinaudo han sugerido para el caso de expresiones culturales ligadas con lo "afro" (Ávila, Pérez y Rinaudo 2011).

En un sistema interconectado, los nuevos mercados van provocando nuevas necesidades de consumo de nuevas mercancías. En su auxilio se desarrollan tecnologías y se estimula un sinfín de innovaciones como parte de un torrente modernizador. Mercado e industria, no obstante, han dejado huecos para hacer visibles los paisajes vernáculos y a sus clandestinos creadores. 
La presencia del gobierno mexicano como garante de esas nuevas articulaciones económicas ha logrado posicionar una construcción estética como dominante y ampliamente visible. La distinción como patrimonio de esa construcción ha requerido de sustentos históricos y culturales cuestionables. El argumento de este documento ha querido mostrar cómo un paisaje es una construcción social, histórica y asimétrica, con un centro, una periferia y una semiperiferia, donde se conjugan paisajes políticos con otros más vernáculos. Una de las consecuencias de encumbrar ciertos artificios e imágenes como únicas y legítimas, es que se relega a la periferia y semiperiferia otras manifestaciones más genuinas. Al hacerlo, se constituye en una política excluyente, donde se invisibilizan y deslegitiman verdaderos patrimonios, pero a la vez se amplían las probabilidades para la aparición de productores clandestinos.

Se trata de un problema de "escala". Las imágenes dominantes abren el lente para sugerir al espectador una homogeneidad visual, un dominio de formas peculiares y atractivas a la mirada por el contraste de sus colores. Sin embargo, la escala micro también debe ser tomada en cuenta al visualizar, admirar o reconocer los paisajes y a sus creadores.

Así las cosas, un bien tangible o intangible, objeto de patrimonialización, resulta un objeto para el mercado, una mercancía. Como tal es una producción, el resultado de formas de relación entre seres humanos. Si el patrimonio es considerado como una mercancía, en lugar de buscarse su conservación por ser una expresión cultural digna de reconocimiento y de preservación en el tiempo como parte de un sistema sociocultural o de una forma de vida, se buscará su continuidad por los beneficios económicos provocados.

Aun cuando algunos de los constructores de esos paisajes o de quienes se ubican en la periferia y semiperiferia no son beneficiados directamente, el dominio de quienes controlan el centro del paisaje agavero ha dejado resquicios para las manifestaciones de los paisajes vernáculos, de los tequilas clandestinos fabricados con materias primas y tecnologías cuyos impactos ecológicos y sociales son más amigables. Las redes de parentesco y de amistad son sólidos canales 
mediante los cuales se intercambian o se comercializan esos productos clandestinos.

La perspicacia de ciertos viajeros y turistas de los paisajes agaveros también ha contribuido a cierta revalorización de esas expresiones culturales más genuinas que la Disneylandia ofertada en el centro del paisaje agavero. Al "bajar la escala" al nivel micro se encuentran genuinas expresiones de los otros paisajes, los que sustentan las expresiones cosméticas rimbombantes.

Luego entonces existe un cuestionamiento cotidiano a las formas de usar pragmáticamente las conceptualizaciones y distinciones internacionales del "paisaje" y del "patrimonio".

Bibliografía

Alonso, Ana María, “The effects of Truth: Re-presentations of the past and the imagining of community", en Journal of historical sociology, vol. 1, núm. 1, Blackwell publishing, marzo 1988, 3357.

ArIzPe, Lourdes, Elpatrimonio cultural inmaterial de México. Ritos y festividades, México, Lx legislatura, Consejo Nacional para la Cultura y las Artes, Centro Regional de Investigaciones Multidisciplinares, Universidad Nacional Autónoma de México, Miguel Ángel Porrúa, 2009.

Ávila Domínguez, Freddy, Ricardo Pérez Montfort y Christian Rinaudo, coords., Circulaciones culturales. Lo afrocaribeño entre Cartagena, Veracruz y La Habana, México, Centro de Investigaciones y Estudios Superiores en Antropología Social, Institut de Recherche pour le Développement, Agence Nationale de la Recherche, Universidad de Cartagena, El Colegio de Michoacán, 2011.

Baudrillard, Jean, Crítica de la economía politica del signo, México, Siglo XXI editores, 1974.

BoeHm, Brigitte, "El lago de Chapala: Su ribera norte. Un ensayo de lectura del paisaje cultural", en Relaciones. Estudios de Historia y Sociedad, vol. xxir, núm. 85, Zamora, El Colegio de Michoacán, invierno 2001, 58-83. 
, Historia ecológica de la cuenca de Chapala, Zamora, El Colegio de Michoacán, Universidad de Guadalajara, 2006.

Bonfil Batalla, Guillermo, "Nuestro patrimonio cultural: un laberinto de significados" en Enrique Florescano, comp., El patrimonio nacional de México, vol. I, México, Fondo de Cultura Económica, 1997, 28-56.

Busquets, Jaume y Albert Cortina, coords., Gestión del paisaje. Manual de protección, gestión y ordenación del paisaje, Barcelona, Ariel, 2009.

Figueroa YÁÑEz, Gonzalo, El patrimonio, 2a edición actualizada con la ley núm. 19,335 de 1994, Chile, Jurídica de Chile, 1995.

Florescano, Enrique, comp., El patrimonio cultural de México, México, Fondo de Cultura Económica, Consejo Nacional para la Cultura y las Artes, 1993.

, coord., El patrimonio nacional de México, vol. I., México, Fondo de Cultura Económica, 1997a.

Galí-Izard, Teresa, Los mismos paisajes. Ideas e interpretaciones, Barcelona, Gustavo Gilli, 2005.

Gómez Arriola, Ignacio, Elpaisaje agavero y las antiguas instalaciones industriales de Tequila, Guadalajara, Cámara Nacional de la Industria Tequilera, Consejo Nacional para la Cultura y las Artes, Instituto Nacional de Antropología e Historia y Gobierno del Estado de Jalisco, 2006.

Gutiérrez y GonzÁlez, Ernesto, El patrimonio. El pecuniario y el moral o derechos de la personalidad, México, Porrúa, 2002.

Hernández López, José de Jesús, El paisaje agavero, expansión y estetización. Ecologia Cultural Política y nuevas formas de creación de valor, Tesis doctoral inédita, Zamora, El Colegio de Michoacán, 2007.

Houston, James, "Paisaje y síntesis geográfica”, en Revista de Geografía, núm. 4, vol. 2, Barcelona, Universidad de Barcelona, Universitat de Lleida, Universitat Rovira i Virgili, 1970, 133-140.

Humboldt, Alejandro de, Ensayo político sobre el reino de la Nueva España, México, Porrúa, 1991.

Illsley Granich, Catarina, "Mezcales campesinos: La opción de la Sansekan Tinemi”, en "La Jornada del Campo", suplemento in- 
formativo de La Jornada, núm. 11, 14 de agosto 2008, Disponible en http://www.jornada.unam.mx/2008/08/14/beber.html Consultado en febrero de 2012.

JaCkson, John B., Discovering the vernacular landscape, New Haven, Yale University Press, 1984.

, A sense of place, a sense of time, New Haven, Yale University Press, 1995.

Jellicoe, Geoffrey y Susan, El paisaje del hombre. La conformación del entorno. Desde la prehistoria hasta nuestros dias, Barcelona, Gustavo Gilli, 2004.

Llull Peñalba, Josué, "Evolución del concepto y de la significación social del patrimonio cultural", en Arte, Individuo y Sociedad, vol. 17, México, 2005, 175-204.

Luna García, Antonio, “QQué hay de nuevo en la nueva geografía cultural?”, en Documentos de los Anales de Geografía, núm. 34, Madrid, 1999, 69-80.

Martignoni, Jimena, Latinscapes. El paisaje como materia prima, Barcelona, Gustavo Gilli, 2008.

Melé, Patrice, "Sacralizar el espacio urbano: el centro de las ciudades mexicanas como patrimonio mundial no renovable", en Alteridades, núm. 8 (16), México, Universidad Autónoma Metropolitana, 1998, 11-26.

Minca, Claudio, "El sujeto, el paisaje y el juego posmoderno", en Joan Nogué, ed., El paisaje en la cultura contemporánea, Madrid, Biblioteca Nueva, 2008, 209-231.

Norton, William, Explorations in the understanding oflandscape: $A$ cultural geography, Westport, Greenwood Press, 1989.

PÉrez-Ruiz, Maya Lorena, "Construcción e investigación del patrimonio cultural. Retos en los museos contemporáneos”, en Alteridades, núm. 8 (16), México, Universidad Autónoma Metropolitana, 1998a, 95-113.

Prats, Llorenc, Antropología y patrimonio, Madrid, Ariel Antropología, 1997.

Rinaudo, Christian, “Lo 'afro', lo popular y lo caribeño en las políticas culturales de Cartagena y Veracruz”, en Freddy Ávila Domínguez, Ricardo Pérez Montfort y Christian Rinaudo, co- 
ords., Circulaciones culturales. Lo afrocaribeño entre Cartagena, Veracruz y La Habana, México, Centro de Investigaciones y Estudios Superiores en Antropología Social, Institut de Recherche pour le Développement, Agence Nationale de la Recherche, Universidad de Cartagena, El Colegio de Michoacán, 2011, 37-67.

Roger, Alain, "Vida y muerte de los paisajes. Valores estéticos, valores ecológicos", en Juan Nogué, ed., El paisaje en la cultura contemporánea, Madrid, Biblioteca Nueva, 2008, 67-85.

SAuer, Carl O., "The morphology of landscape", en Publications in Geography, 2 (2), University of California, 1925, 19-53.

Thiébaut, Virginia, Magdalena García Sánchez y María Antonieta Jiménez Izarraraz, eds., Patrimonio y paisajes culturales, Zamora, El Colegio de Michoacán, 2008.

Toledo, Alejandro, Agua, hombre y paisaje, México, InE-SEMARnAT, Ciesas, 2006.

Tovar y DE Teresa, R., "Hacia una nueva política cultural”, en Enrique Florescano, coord., El patrimonio nacional de México, vol. I, México, Fondo de Cultura Económica, 1997a.

VIQUeIRA, Carmen, El enfoque regional en antropología, México, Universidad Iberoamericana, 2001.

WALlERSTEIN, Immanuel, El moderno sistema mundial. La agricultura capitalista y los origenes de la economía-mundo europea en el siglo XVI, vol. I, México, Siglo XXI editores, 2004.

, El mercantilismo y la consolidación de la economía-mundo europea, 1600-1750, México, Siglo XXI editores, 2005.

El moderno sistema mundial. La segunda era de gran expansión de la economía-mundo capitalista. 1730-1850, vol. III, México, Siglo XXI editores, 2007.

Weigand, Phil, "Evaluación de paisajes culturales: Los pasos en arqueología”, Ponencia presentada en homenaje a Brigitte Boehm, Zamora, El Colegio de Michoacán, Inédita, 2007, s/p.

Zoido NARANJo, Florencio, "El paisaje y su utilidad para la ordenación del territorio", en Geocalli. Cuadernos de Geografía, Desarrollo territorial y paisaje, año 7, núm. 14, Guadalajara, Universidad de Guadalajara, septiembre 2006, 69-125. 
PÁginas De internet

CINU, "La importancia del patrimonio cultural", 2002, Artículo en línea disponible en http://www.cinu.org.mx/eventos/cultura2002/importa.htm Consultada el 20 de diciembre de 2008.

SAuer, Carl O., "La gestión del hombre en la tierra", Conferencia en Simposio "El papel del hombre en el cambio de la faz de la tierra", Nueva Jersey, Princeton, 1956, Tomado de William Thomas, ed., Man's role in changing the face of the Earth, Chicago, The University of Chicago Press, 1967. Disponible en http:// www.colorado.edu/geography/giw/sauer-co/sauer-co.html Consultado en diciembre de 2008.

Vigna, Anne, "Los falsarios del ecoturismo. Grandes proyectos privados en América Central", Le monde diplomatique, julio 2006, Artículo en línea disponible en http://www.lemondediplomatique.cl/Los-falsarios-del-ecoturismo.html Consultado el 20 de diciembre de 2008.

FeCHA DE RECEPCión DEL ARTículo: 10 de enero de 2013

FECHA DE RECEPCIÓN DE LA VERSIÓN FINAL: 25 de marzo de 2013 